University of Wollongong

Research Online

Faculty of Engineering and Information

Faculty of Engineering and Information

Sciences - Papers: Part A

Sciences

$1-1-2014$

\title{
Solar PV and battery storage integration using a new configuration of a three-level NPC inverter with advanced control strategy
}

Hamid Teymour Ghasemabadi

University of Wollongong, hrtg176@uowmail.edu.au

Danny Soetanto

University of Wollongong, soetanto@uow.edu.au

Kashem M. Muttaqi

University of Wollongong, kashem@uow.edu.au

Philip Ciufo

University of Wollongong, ciufo@uow.edu.au

Follow this and additional works at: https://ro.uow.edu.au/eispapers

Part of the Engineering Commons, and the Science and Technology Studies Commons

Research Online is the open access institutional repository for the University of Wollongong. For further information contact the UOW Library: research-pubs@uow.edu.au 


\title{
Solar PV and battery storage integration using a new configuration of a three- level NPC inverter with advanced control strategy
}

\author{
Abstract \\ In this paper, a novel configuration of a three-level neutral-point-clamped (NPC) inverter that can integrate \\ solar photovoltaic (PV) with battery storage in a grid-connected system is proposed. The strength of the \\ proposed topology lies in a novel, extended unbalance three-level vector modulation technique that can \\ generate the correct ac voltage under unbalanced dc voltage conditions. This paper presents the design \\ philosophy of the proposed configuration and the theoretical framework of the proposed modulation \\ technique. A new control algorithm for the proposed system is also presented in order to control the \\ power delivery between the solar PV, battery, and grid, which simultaneously provides maximum power \\ point tracking (MPPT) operation for the solar PV. The effectiveness of the proposed methodology is \\ investigated by the simulation of several scenarios, including battery charging and discharging with \\ different levels of solar irradiation. The proposedmethodology and topology is further validated using an \\ experimental setup in the laboratory.

\section{Keywords} \\ storage, three, pv, battery, solar, control, strategy, advanced, integration, inverter, npc, level, configuration

\section{Disciplines} \\ Engineering | Science and Technology Studies

\section{Publication Details} \\ H. R. Teymour , D. Sutanto, K. M. Muttaqi \& P. Ciufo, "Solar PV and battery storage integration using a new \\ configuration of a three-level NPC inverter with advanced control strategy," IEEE Transactions on Energy \\ Conversion, vol. 29, (2) pp. 354-365, 2014.
}




\title{
Solar PV and Battery Storage Integration using a New Configuration of a Three-Level NPC Inverter with Advanced Control Strategy
}

\author{
H. R. Teymour, Student Member, IEEE, D. Sutanto, Senior Member, IEEE, and K. M. Muttaqi, Senior \\ Member, IEEE, P. Ciufo, Senior Member, IEEE
}

\begin{abstract}
In this paper, a novel configuration of a three-level neutral point clamped (NPC) inverter that can integrate solar PV with battery storage in a grid-connected system is proposed. The strength of the proposed topology lies in a novel, extended unbalance three-level vector modulation technique that can generate the correct $\mathrm{AC}$ voltage under unbalanced $\mathrm{DC}$ voltage conditions. This paper presents the design philosophy of the proposed configuration and the theoretical framework of the proposed modulation technique. A new control algorithm for the proposed system is also presented in order to control the power delivery between the solar PV, battery, and grid, which simultaneously provides maximum power point tracking (MPPT) operation for the solar PV. The effectiveness of the proposed methodology is investigated by the simulation of several scenarios, including battery charging and discharging with different levels of solar irradiation. The proposed methodology and topology is further validated using an experimental setup in the laboratory.
\end{abstract}

Index Terms--Battery storage, space vector modulation (SVM), solar photovoltaic (PV), three-level inverter.

\section{INTRODUCTION}

$\mathrm{D}$ UE to the world energy crisis and environmental problems caused by conventional power generation, renewable energy sources such as photovoltaic (PV) and wind generation systems are becoming more promising alternatives to replace conventional generation units for electricity generation [1], [2].

Advanced power electronic systems are needed to utilize and develop renewable energy sources. In solar PV or wind energy applications, utilizing maximum power from the source is one of the most important functions of the power electronic systems [3]-[5]. In three-phase applications, two types of power electronic configurations are commonly used to transfer power from the renewable energy resource to the grid: single-stage and double-stage conversion. In the doublestage conversion for a PV system, the first stage is usually a $\mathrm{DC} / \mathrm{DC}$ converter and the second stage is a $\mathrm{DC} / \mathrm{AC}$ inverter. The function of the DC/DC converter is to facilitate the maximum power point tracking (MPPT) of the PV array and

Hamid R. Teymour, Danny Sutanto, Kashem M. Muttaqi and Phil Ciufo are with the Endeavour Energy Power Quality and Reliability Centre, School of Electrical, Computer and Telecommunications Engineering, University of Wollongong, NSW 2522, Australia (Emails: hrtg176@uowmail.edu.au; saetanto@uow.edu.au; kashem@uow.edu.au; ciufo@uow.edu.au). to produce the appropriate $\mathrm{DC}$ voltage for the $\mathrm{DC} / \mathrm{AC}$ inverter. The function of the inverter is to generate three-phase sinusoidal voltages or currents to transfer the power to the grid in a grid-connected solar PV system or to the load in a standalone system [3]-[5].

In the single-stage connection, only one converter is needed to fulfill the double-stage functions, and hence the system will have a lower cost and higher efficiency, however, a more complex control method will be required. The current norm of the industry for high power applications is a three-phase, single-stage PV energy systems by using a voltage source converter (VSC) for power conversion [4].

One of the major concerns of solar and wind energy systems is their unpredictable and fluctuating nature. Gridconnected renewable energy systems accompanied by battery energy storage can overcome this concern. This also can increase the flexibility of power system control and raise the overall availability of the system [2]. Usually a converter is required to control the charging and discharging of the battery storage system and another converter is required for DC/AC power conversion; thus a three-phase $\mathrm{PV}$ system connected to battery storage will require two converters. This paper is concerned with the design and study of a grid-connected threephase solar PV system integrated with battery storage using only one three-level converter having the capability of MPPT and $\mathrm{AC}$ side current control, and also the ability of controlling the battery charging and discharging. This will result in lower cost, better efficiency and increased flexibility of power flow control.

The remainder of the paper is organized as follows. Section II describes the structure of a three-level inverter and associated capacitor voltages. Section III presents the proposed topology to integrate solar PV and battery storage and its associated control. Section IV describes the simulation and validation of the proposed topology and associated control system. Section V describes the prototype of the proposed topology and the experimental results. Section VI concludes the paper.

\section{STRUCTURE OF A THREE-LEVEL INVERTER AND ITS CAPACITOR VOLTAGE CONSIDERATIONS}

\section{A. Three-Level Inverter}

Since the introduction of three-level inverters in 1981 [6], [7], they have been widely used in several applications, such 
as: motor drives, STATCOM, HVDC, pulse-width modulation (PWM) rectifiers, active power filters (APFs) and renewable energy applications [7], [8]. Fig. 1(a) shows a typical threephase three-level NPC inverter circuit topology. The converter has two capacitors in the DC side to produce the three-level AC side phase voltages. Normally, the capacitor voltages are assumed to be balanced, since it has been reported that unbalance capacitor voltages can affect the AC side voltages and can produce unexpected behavior on system parameters such as even-harmonic injection and power ripple [7], [9]. Several papers have discussed methods of balancing these capacitor voltages in various applications [6], [7], [9]-[16].

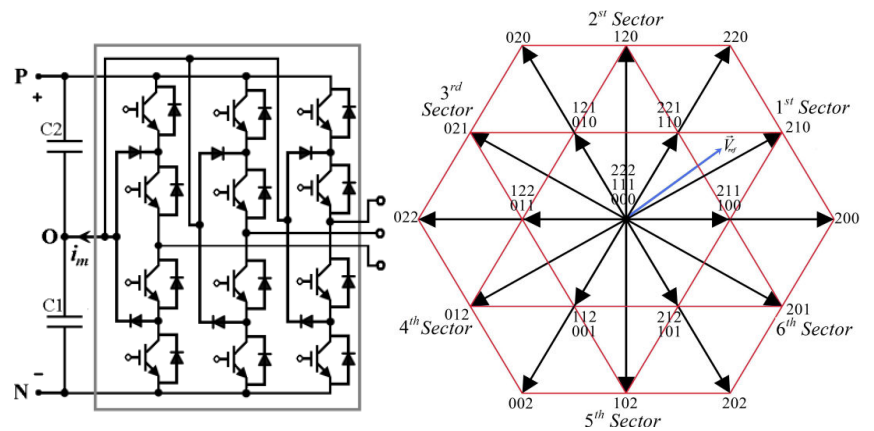

Fig. 1. A typical three-level inverter (a) structure of circuit, and (b) three-level inverter space vector diagram for balanced DC-link capacitors [6]

\section{B. Balanced Capacitors Voltage}

Various strategies have been proposed to balance the capacitor voltages using modulation algorithms such as sinusoidal carrier-based PWM (SPWM) or space vector pulsewidth modulation (SVPWM) [17].

In SPWM applications, most of the strategies are based on injecting the appropriate zero-sequence signal into the modulation signals to balance the DC-link capacitors [12], [13], [16], [18].

In SVPWM applications, a better understanding of the effects of the switching options on the capacitor voltages in the vector space has resulted in many strategies proposed to balance capacitors voltages in the three-level NPC inverter. These include capacitor balancing using conventional SVPWM, virtual SVPWM (VSVPWM) and their combination [14], [15], [19].

In vector control theory, ideally, the inverter must be able to generate the voltage output instantaneously, following the reference vector, $\left(\vec{V}_{r e f}\right)$, generated by the control system. However because of the limitation of the switches in the inverter, it is not possible to guarantee that any requested vector can be generated; as a matter of fact, only a limited number of vectors ( 27 vectors for three-level inverter) can be generated.

To overcome such difficulties, in any space vector modulation scheme such as SVPWM and VSVPWM, the reference vector, $\vec{V}_{\text {ref }}$, is generated by selecting the appropriate available vectors in each time frame in such a way that the average of the applied vectors must be equal to the reference vector.

Equation (1) shows the mathematical relation between the timing of the applied vectors and the reference vector.

$$
\left\{\begin{array}{c}
T_{s} \vec{V}_{r e f}=\sum_{i=1}^{n} T_{i} \vec{V}_{i} \\
T_{s}=\sum_{i=1}^{n} T_{i}
\end{array}\right.
$$

where, $T_{S}$, is the time frame and preferred to be as short as possible. It can be considered as a control update period where an average vector will be mathematically generated during this time duration. $T_{i}$ is the corresponding time segment for selected inverter vector $\vec{V}_{i}$ and $n$ is the number of applied vectors.

Generally, the reference vector is generated by three different vector $(n=3)$, and (1) can be converted to three different equation with three variables $T_{1}, T_{2}$ and $T_{3}$ to be calculated. Several vector PWM techniques presented in [6], [7], [9]-[11] and [13]-[15] apply similar technique of timing calculation.

Fig. 1(b) shows the space vector diagram of a three-level inverter for balanced DC-link capacitors [6]. It is made up of 27 switching states, from which 19 different voltage vectors can be selected. The number associated with each vector in Fig. 1(b) represents the switching state of the inverter phases respectively. The voltage vectors can be categorized into five groups, in relation to their amplitudes and their effects on different capacitor voltages from the view of the inverter $\mathrm{AC}$ side. They are six long vectors $(200,220,020,022,002$, and $202)$, three zero vectors $(000,111$, and 222), six medium vectors $(210,120,021,012,102$, and 201), six upper short vectors $(211,221,121,122,112$, and 212) and six lower short vectors $(100,110,010,011,001$, and 101).

For generating $\vec{V}_{r e f}$, when one of the selections $\left(\vec{V}_{i}\right)$ is a short vector, then there are two choices that can be made which can produce exactly the same effect on the AC side of the inverter in the three wire connection (if voltages are balanced). For example, the short vector ' 211 ' will have the same effect as ' 100 ' on the $\mathrm{AC}$ side of the inverter. However, this choice will have different effect on the DC side, as it will cause a different DC capacitor to be chosen for the transfer of power from or to the AC side, and a different capacitor will be charged or discharged depending on the switching states and the direction of the AC side current. For example, Fig. 2 shows the connection of the capacitors when ' 100 'or ' 211 ' is selected, demonstrating how different capacitors are involved in the transfer of power.

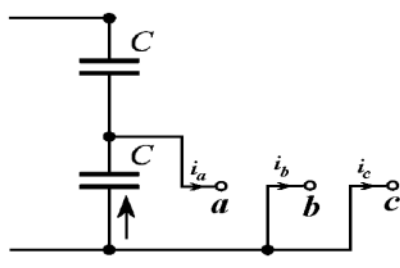

(a) Short vector -100

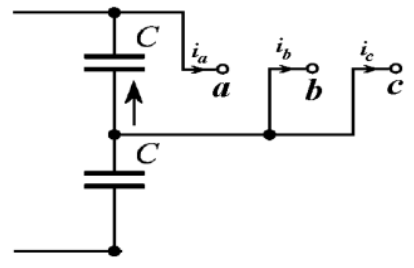

(b) Short vector - 211
Fig. 2. Equivalent circuit and capacitors current with two different short vector

Capacitor balancing in most reported three-level NPC inverter applications is achieved by the proper selection of the short vectors. In order to produce the AC side waveform, the vector diagram of Fig. 1(b) is used, where the DC capacitor 
voltages are assumed to be balanced. Fig. 1(b) can then be used to determine the appropriate vectors to be selected and to calculate their corresponding timing $\left(T_{i}\right)$ for implementing the required reference vector based on the expression given in (1). Although the control system is trying to ensure balanced capacitor voltages, should any unbalance occur during a transient or an unexpected operation, the above method will produce an inaccurate $\mathrm{AC}$ side waveform which can be different from the actual requested vector by the control system. This can result in the production of even-harmonics, unbalanced current and unpredicted dynamic behavior.

However, in some applications, the requirement of having balanced capacitor voltages may be too restrictive. It is possible to work with either balanced or unbalanced capacitor voltages. The method proposed in this paper is based on the freedom of having balance or unbalanced capacitor voltages. In such applications, it is important to be able to generate an accurate reference vector based on (1), irrespective of whether the capacitor voltages are balanced or not, to achieve the desired objectives of the system.

\section{Unbalanced Capacitor Voltages}

Fig. 3 shows a general structure of a grid-connected threelevel inverter showing the $\mathrm{DC}$ and $\mathrm{AC}$ sides of the inverter. The DC side system, shown as ' $N$ ' can be made up of many circuit configurations, depending on the application of the inverter. For instance, the DC side system can be a solar PV, a wind generator with a rectifying circuit, a battery storage system or a combination of these systems where the DC voltage across each capacitor can be different or equal. One of the main ideas of this paper is to have an overall view of the switching effects on a three-wire connection of a three-level NPC inverter with a combination of these systems on the DC side.

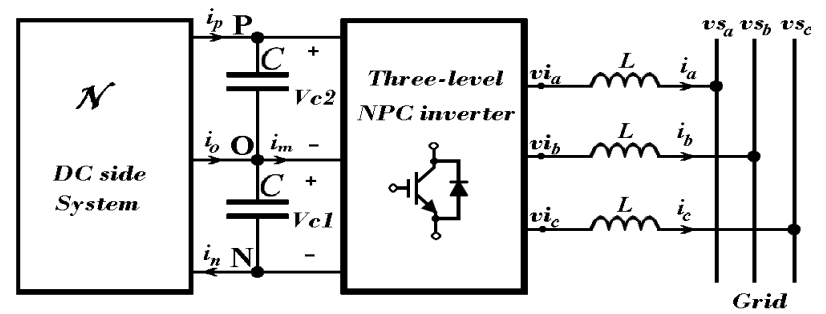

Fig. 3. The general diagram of a grid connected three-wire three-level inverter

Mathematically, in a three-wire connection of a two-level inverter, the $d q 0$ field, $v_{d}, v_{\mathrm{q}}$, and $v_{0}$ of the inverter in vector control can be considered as having two degrees of freedom in the control system; because the zero sequence voltage, $v_{0}$, will have no effect on the system behavior in both the DC and the $\mathrm{AC}$ side of the inverter. However, in the three-level three-wire application illustrated in Fig. 3, with fixed $v_{\mathrm{d}}$ and $v_{\mathrm{q}}$, although $v_{0}$ will have no effect on the AC side behavior, it can be useful to take advantage of $v_{0}$ to provide a new degree of freedom to control the sharing of the capacitor voltages in the DC bus of the inverter. By doing this, it is now possible to operate and control the inverter under both balanced and unbalanced capacitor voltages while continuing to generate the correct voltages in the AC side. This feature is particularly useful in applications where the two capacitor voltages can be different, such as when connecting two PV modules with different MPPT points, or connecting a PV module across the two capacitors and including battery storage at the mid-point of the two capacitors, or connecting battery storage to each of the capacitors with the ability to transfer different power from each battery storage.

\section{The effect of unbalanced capacitor voltages on the vector diagram}

In the vector diagram shown in Fig. 1(b), capacitor voltage unbalance causes the short and medium vectors to have different magnitudes and angles compared to the case when the capacitor voltages are balanced. Fig. 4 shows the differences between two cases as highlighted in the first sector of the sextant in Fig. 1(b) for $V_{C 1}<V_{C 2}$. Vector related to the switching state, $\vec{V}_{I}$ can be calculated as follows [20]:

$$
\overrightarrow{V_{I}}=\frac{2}{3}\left(V_{a N}+\vec{a} V_{b N}+\vec{a}^{2} V_{c N}\right)
$$

where $\vec{a}=\mathrm{e}^{\mathrm{j}\left(\frac{2 \pi}{3}\right)}$ and $V_{\mathrm{aN}}, V_{\mathrm{bN}}$ and $\mathrm{V}_{\mathrm{cN}}$ are the voltage values of each phase with reference to ' $N$ ' in Fig. 1(a). Assuming that the length of the long vectors $\left(\frac{2}{3} V d c\right)$ is 1 unit and the voltage of capacitor $C_{1}, V c_{1}=h V d c$, for $0 \leq h \leq 1$, then the vectors in the first sector can be calculated using (2) and the results are given in (3)-(9).
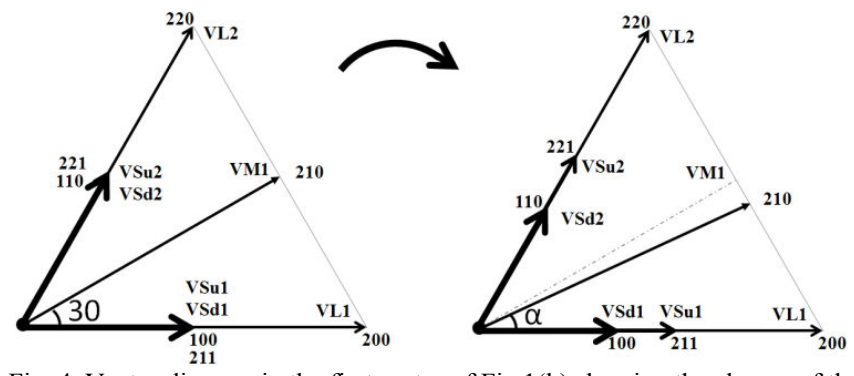

Fig. 4. Vector diagram in the first sector of Fig 1(b) showing the change of the vectors using balanced DC and unbalanced DC assuming $\mathrm{Vc} 1<\mathrm{Vc} 2$.

$$
\begin{aligned}
& \vec{V} s d 1=h \\
& \vec{V} s u 1=1-h \\
& \vec{V} l 1=1 \\
& \vec{V} l 2=\frac{1}{2}+\frac{\sqrt{3}}{2} j \\
& \vec{V} s d 2=h\left(\frac{1}{2}+\frac{\sqrt{3}}{2} j\right) \\
& \vec{V} s u 2=(1-h)\left(\frac{1}{2}+\frac{\sqrt{3}}{2} j\right) \\
& \vec{V} m 1=\left(1-\frac{h}{2}\right)+h \frac{\sqrt{3}}{2} j
\end{aligned}
$$

The vectors in the other sectors can be calculated similarly. Equations (3-9) show that the magnitudes and the angles of the vectors can change depending on the value of the capacitor voltages. For example, when $h=0.5$, then the two capacitor voltages are the same and the two short vectors are the same, $\vec{V} s l 1=\vec{V} s u 1$. However, when the two capacitor voltages are different, the vectors will have different magnitudes. Since the short vectors are now different in magnitude, the choice of these short vectors will now have a different effect on both the DC and AC side. 
Traditionally, each pair of short vectors is considered to be redundant, as the selection of any of the short vectors at any instance will have the same effect on the AC side. However, when the two capacitor voltages are different, the short vectors cannot be considered to be redundant any more. Thus, when $h \neq 0.5$, each different short vector needs different timing to generate the requested vector based on (1).

\section{$E$. Selecting vectors under unbalanced DC voltage condition} and their effects on the AC side of inverter

To generate a reference vector based on (1), different combinations can be implemented. Fig. 5 shows different possible vector selections to generate a reference vector $\left(\vec{V}^{*}\right)$ in the first sector based on the selections of different short vectors. For example, to generate $\vec{V}^{*}$ based on Fig. 5(a), one of following combinations can be selected with proper timing based on (1). The combinations are: $(221-210-100),(221-$ 220 - 100), (221 - 200 - 100), (221 - 200 - Zero), (000 - 220 Zero), (220 - 200 - Zero), where 'Zero' can be '000' or ' 111 ' or ' 222 '. This demonstrates that there is flexibility in choosing the correct vector selections. Although all of these selections with suitable timing can generate the same reference vector, they have different impacts on the DC and AC side of the inverter in their instantaneous behavior.

To investigate the AC side behavior, the accuracy of the generated voltage must be examined.
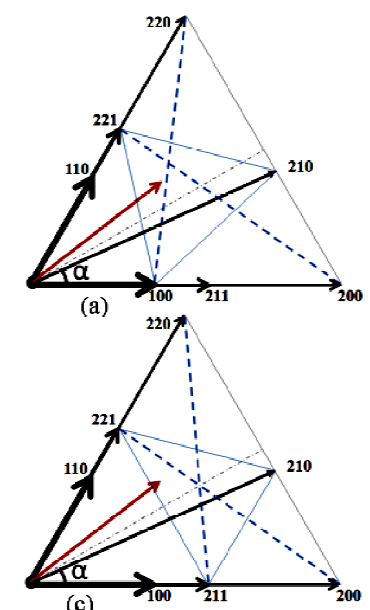
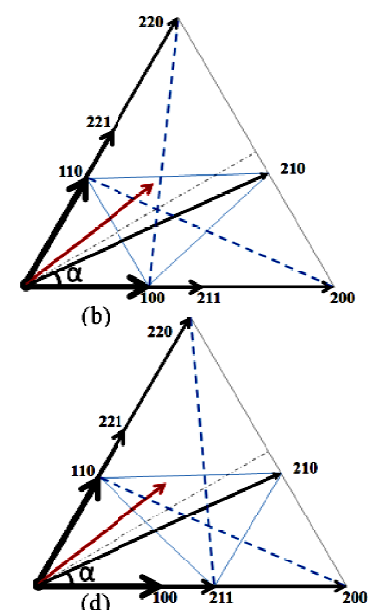

Fig.5. Different possible vector selection ideas.

As far as the AC side is concerned, ideally the requested voltage, $\vec{V}^{*}(t)$, should be exactly and simultaneously generated in the three phases of the inverter to have the correct instantaneous current in the AC side of the system. However, because of the limitation of the inverter to generate the exact value of the requested voltage in each phase, in the short time, $T_{S}$, only the average value of the requested vector $\vec{V}^{*}$ for the specified time window of $\mathrm{T}_{\mathrm{s}}$ can be produced.

To investigate the continuous time behavior of the AC side voltages, the error vector, $\vec{e}(t)$, can be calculated in order to determine how far the generated voltage deviates from the requested vector as follows:

$$
\vec{e}(t)=\vec{V}^{*}(t)-\vec{V}_{a p l}(t)
$$

$$
E(t) \triangleq\left|\int_{0}^{t} \vec{e}(t) d t\right| ; 0 \leq t \leq T_{S}
$$

where $\vec{V}_{a p l}(t)$ is the applied vector at the time ' $t$ '. This error can result in harmonic current across the impedance connected between the inverter and the grid. If this impedance is an inductor then the ripple in the inductors current, $\overrightarrow{I r_{L}}$, can be expressed as:

$$
\overrightarrow{I r_{L}}=1 / L \int_{0}^{t} \vec{e}(t) d t
$$

where $\vec{e}(t)$ is defined as:

$$
\vec{e}(t) \triangleq L \frac{d \overrightarrow{I r_{L}}}{d t}
$$

To derive (13), it is assumed that the requested vector, $\vec{V}^{*}(t)$, will generate sinusoidal current in the inductor, which is normally acceptable in the continuous time behavior of the system. Based on (11) and (12), the absolute value of error $E(t)$ is directly related to the magnitude of the inductors current ripple. Although based on (1) and (11), $E\left(T_{S}\right)=0$ or the sum of errors during the period $T_{S}$ is zero; but to reduce the magnitude of high frequency ripples, it is important to minimize the error at each time instant. To achieve this, the three nearest vectors (TNV) are usually used. For example, in Fig. 5(a), to generate the requested vector $\vec{V}^{*}$, in the TNV method, the group $(221,210,100$ or 211$)$ appears to be the best three nearest vectors to be chosen.

Also, to reduce $E(t)$, a smart timing algorithm for each vector in the TNV method has been proposed, such as dividing the time to apply each vector into two or more shorter times. However, this will have the effect of increasing switching losses. Dividing by two is common, acceptable solution. Moreover, reducing $T_{s}$ will reduce the error $E(t)$ while improving the accuracy of the requested vector generated by the control system. According to the basic rule of digital control, accuracy of the requested vector calculation can be improved by reduction of the sampling time and the vector calculation time.

\section{$F$. Selecting vectors under unbalanced DC voltage conditions and their effects on DC side of the inverter}

As far as the DC side is concerned, different vectors have different effects on the capacitor voltages which depend on the sum of the incoming currents from the DC side and the inverter side.

Fig. 3 shows $i_{p}, i_{o}$ and $i_{n}$ as DC-side system currents which are dependent on the DC-side system circuit topology and capacitor voltages. The currents coming from the inverter are related to the inverter switching and the $\mathrm{AC}$ side of inverter currents which can be directly affected by the implemented vectors in the inverter. Selecting different vectors will transfer AC side currents and power differently to the capacitors as discussed in Section II-B.

The instantaneous power transmitted to the DC side of the inverter from the $\mathrm{AC}$ side can be calculated as follows:

$$
p(t)=v_{I a} \cdot i_{a}+v_{I b} \cdot i_{b}+v_{I c} \cdot i_{c}
$$

where $v_{I a}, v_{I b}$ and $v_{I c}$ are the $\mathrm{AC}$ side inverter instantaneous voltages with reference to the ' $\mathrm{N}$ ' point, and $i_{a}, i_{b}, i_{c}$ are 
inverter currents.

For example, in the first sector of the vector diagram shown in Fig. 4, $p(t)$ for the short vectors can be expressed by the following equations:

$$
\begin{aligned}
& \left\{\begin{array}{c}
p_{211}(t)=(1-h) V d c * i_{a} \\
p_{100}(t)=h V d c *\left(-i_{a}\right)
\end{array}\right. \\
& \left\{\begin{array}{c}
p_{221}(t)=(1-h) V d c *\left(-i_{c}\right) \\
p_{110}(t)=h V d c * i_{c}
\end{array}\right.
\end{aligned}
$$

Ignoring the DC-side system behavior, selecting the upper short vectors, '211' and '221', will affect the upper capacitor voltage, and selecting the lower short vectors, ' 100 ' and ' 110 ' will affect the lower capacitor voltage. For example, when $i_{a}>0$, if vector ' 211 ' is selected, it will charge the upper capacitor without any effect on the lower capacitor voltage and if vector 100 is selected, it will discharge the lower capacitor without having any effect on the upper capacitor voltage. By using (15) and (16), the rate of charging and discharging and their dependency on the $h$ and $V_{d c}$ values and inverter currents can also be observed. However, for accurate investigations, the DC side system behavior needs to be considered in the control of charging and discharging rates of the capacitor voltages.

\section{PROPOSED TOPOLOGY TO INTEGRATE SOLAR PV AND BATTERY STORAGE AND ITS ASSOCIATED CONTROL}

A. Proposed topology to integrate solar PV and battery storage using an improved unbalanced DC functionality of a three-level inverter

Based on the discussions in Section I and II, two new configurations of a three-level inverter to integrate battery storage and solar PV shown in Fig. 6 are proposed, where no extra converter is required to connect the battery storage to the grid connected PV system. These can reduce the cost and improve the overall efficiency of the whole system particularly for medium and high power applications.

Fig. 6(a) shows the diagram of the basic configuration. In the proposed system, power can be transferred to the grid from the renewable energy source while allowing charging and discharging of the battery storage system as requested by the control system. The proposed system will be able to control the sum of the capacitor voltages $\left(V_{C 1}+V_{C 2}=V_{d c}\right)$ to achieve the MPPT condition and at the same time will be able to control independently the lower capacitor voltage $\left(V_{C l}\right)$ that can be used to control the charging and discharging of the battery storage system. Further, the output of the inverter can still have the correct voltage waveform with low THD current in the AC side even under unbalanced capacitor voltages in the DC side of the inverter.

Although this configuration can operate under most conditions, however when the solar PV does not produce any power, the system cannot work properly with just one battery.

Fig. 6(b) shows the improved configuration where two batteries are now connected across two capacitors through two relays. When one of the relays is closed and the other relay is open, the configuration in Fig. 6(b) is similar to that in Fig. 6(a) which can charge or discharge the battery storage while the renewable energy source can generate power. However, when the renewable energy is unavailable, both relays can be closed allowing the DC bus to transfer or absorb active and reactive power to or from the grid. It should be noted that these relays are selected to be $\mathrm{ON}$ or OFF as required; there is no PWM control requirement. This also provides flexibility in managing which of the two batteries is to be charged when power is available from the renewable energy source or from the grid. When one of the batteries is fully charged, the relay connected to this battery can be opened while closing the relay on the other battery to charge. Special consideration needs to be made to ensure that current through the inductor $L_{\text {batt }}$ must be zero prior to opening any of these relays to avoid disrupting the inductor current and also to avoid damaging the relay.

\section{B. Control topology}

In Fig. 6(b), three different relay configurations can be obtained: (i) when the top relay is closed, (ii) when the bottom relay is closed and (iii) when both relays are closed. Fig. 7 shows the block diagram of the control system for configuration (i).
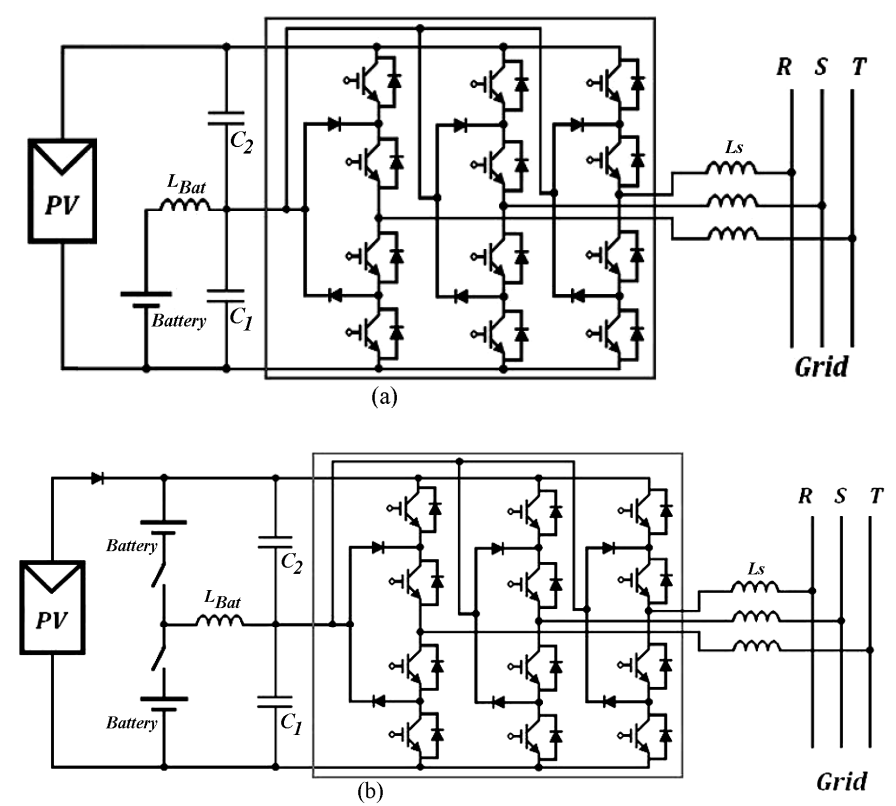

Fig.6. Proposed configurations for integrating solar PV and battery storage. (a) a basic configuration (b) an improved configuration

In Fig. 7, the requested active and reactive power generation by the inverter to be transferred to the grid will be determined by the network supervisory block. This will be achieved based on the available PV generation, the grid data and the current battery variables.

The MPPT block determines the requested DC voltage across the PV to achieve the MPPT condition. This voltage can be determined by using another control loop, with slower dynamics, using the measurement of the available PV power. The details of the MPPT algorithm to determine the desired voltage $\left(V_{d c}^{*}\right)$ can be found in [3] and [4]

Based on the requested active $\left(p^{*}\right)$ and reactive power $\left(q^{*}\right)$, and the grid voltage in the dq-axis, $v_{s d}$ and $v_{s q}$, the requested inverter current in the dq-axis, $i_{d}$ and $i_{q}$ can be obtained using (17): 


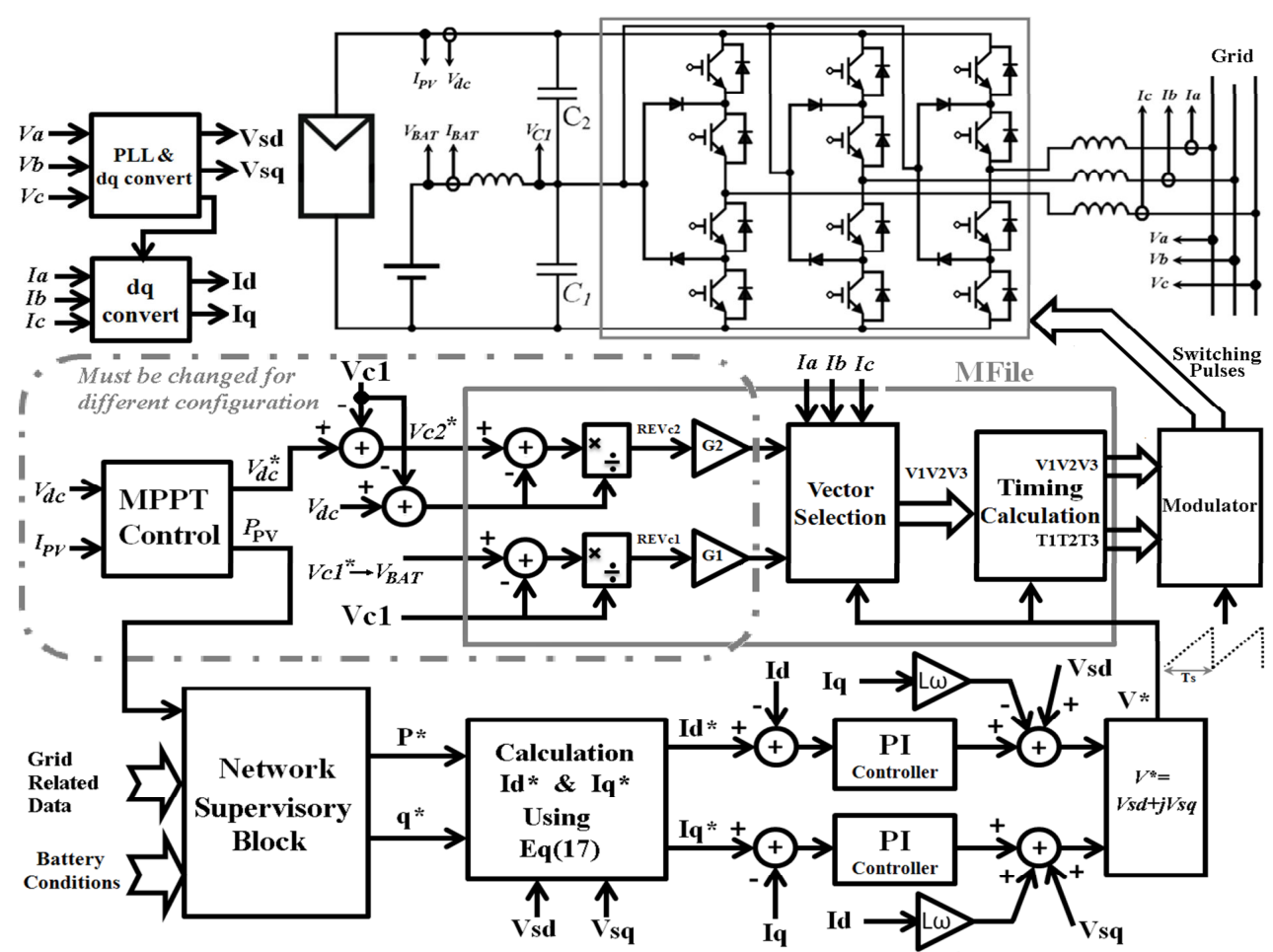

Fig. 7. Control system diagram to integrate PV and battery storage

$$
\begin{aligned}
& \left\{\begin{array}{l}
p=v_{s d} i_{d}+v_{s q} i_{q} \\
q=v_{s q} i_{d}+v_{s d} i_{q}
\end{array} \Rightarrow\right. \\
& i_{d}^{*}=\frac{p^{*} v_{s d}-q^{*} v_{s q}}{v_{s d^{2}}+v_{s q}{ }^{2}} ; i_{q}^{*}=\frac{q^{*} v_{s d}-p^{*} v_{s q}}{v_{s d^{2}+v_{s q}}}
\end{aligned}
$$

By using a proportional and integral (PI) controller and decoupling control structure, the inverter requested voltage vector can be calculated. The proposed control system is shown in Fig. 7. In the proposed system, to transfer a specified amount of power to the grid, the battery will be charged using surplus energy from the PV or will be discharged to support the PV when the available energy cannot support the requested power.

After evaluating the requested reference voltage vector, the appropriate sector in the vector diagram can be determined. To determine which short vectors are to be selected, the relative errors of capacitor voltages given in (18) and (19) are used;

$$
\begin{aligned}
& e_{V c 1}=\left(V_{C 1}^{*}-V_{C 1}\right) / V_{C 1} \\
& e_{V c 2}=\left(V_{C 2}^{*}-V_{C 2}\right) / V_{C 2}
\end{aligned}
$$

where $\mathrm{V}_{\mathrm{C} 1}^{*}$ and $\mathrm{V}_{\mathrm{C} 2}^{*}$ are the desired capacitor voltages, and $\mathrm{V}_{\mathrm{C} 1}$ and $\mathrm{V}_{\mathrm{C} 2}$ are the actual capacitor voltages for capacitor $\mathrm{C}_{1}$ and $\mathrm{C}_{2}$ respectively.

The selection of the short vectors will determine which capacitor is to be charged or discharged. To determine which short vector must be selected, the relative errors of capacitor voltages and their effectiveness on the control system behavior are important. A decision function ' $F$ ', as given in (20), can be defined based on this idea.

$$
F=G_{1} e_{V c 1}-G_{2} e_{V c 2}
$$

where $G_{1}$ and $G_{2}$ are the gains associated with each of the relative errors of the capacitor voltages.

$G_{1}$ and $G_{2}$ are used to determine which relative error of the capacitor voltages is more important and consequently allows better control of the chosen capacitor voltage. For example, for an application that requires the balancing of the capacitor voltages as in traditional three-level inverters, $G_{1}$ and $G_{2}$ must have the same value with equal reference voltage values, but in the proposed application where the capacitor voltages can be unbalanced, $G_{1}$ and $G_{2}$ are different and their values are completely dependent on their definitions of desired capacitor voltages. By using $V_{C 2}^{*}=V_{d c}^{*}-V_{C 1}$ and $V_{C 1}^{*}=\mathrm{V}_{\mathrm{BAT}}$ and selecting $G_{2}$ much higher than $G_{1}$, the PV can be controlled to the MPPT, and $\mathrm{C}_{1}$ voltage can be controlled to allow charging and discharging of the battery.

In each time step, the sign of $F$ is used to determine which short vectors are to be chosen. When $F$ is positive, the short vectors need to be selected that can charge $C_{1}$ or discharge $C_{2}$ in that particular time step by applying (14) and using similar reasoning to (15) and(16). Similarly, when $F$ is negative, the short vectors need to be selected that can charge $\mathrm{C}_{2}$ or discharge $\mathrm{C}_{1}$ in that particular time step.

Based on the control system diagram given in Fig. 7, on the AC side, the requested active power, $p^{*}$, and reactive power, $q^{*}$, will be generated by the inverter by implementing the requested voltage vector and applying the proper timing of the applied vectors. Further, on the DC side, MPPT control can be achieved by strict control of $V_{C 2}\left(G_{2}>G_{1}\right)$ with reference 
value of $\left(V_{d c}^{*}-V_{C 1}\right)$ and more flexible control of $V_{C 1}$ with reference value of the battery voltage, $\mathrm{V}_{\mathrm{BAT}}$. By using the decision function $(F)$ with the given reference values, the proper short vectors to be applied to implement the requested vector can be determined. With MPPT control, the PV arrays can transfer the maximum available power $\left(P_{\mathrm{PV}}\right)$ and with generating the requested vector in the $\mathrm{AC}$ side, the requested power, $P^{*}$, is transferred to the grid. Then the control system will automatically control $V_{C 1}$ to transfer excess power, $\left(\mathrm{P}_{\mathrm{PV}}-\right.$ $\left.P^{*}\right)$ to the battery storage or absorb the power deficit, $\left(P^{*}-\right.$ $\mathrm{P}_{\mathrm{PV}}$ ) from the battery storage.

The same control system is applicable for configuration (ii) by changing the generated reference voltages for the capacitors. Configuration (iii) represents two storage systems connected to grid without any PV contribution, such as at night when the PV is not producing any output.

\section{SimUlATION AND VALIDATION OF THE PROPOSED TOPOLOGY AND CONTROL SYSTEM}

Simulations have been carried out using MATLAB/Simulink to verify the effectiveness of the proposed topology and control system. An LCL filter is used to connect the inverter to the grid. Fig. 8 shows the block diagram of the simulated system.

Three, series-connected PV modules are used in the simulation. The mathematical model of each of the PV units is given in (21) [21] and used in the simulation.

$I_{P V}=I_{S C}-10^{-7}\left(e^{\left(\frac{V_{P V}}{2574 \times 10^{-3}}\right)}-1\right)$

where $I_{S C}$ is the short circuit current of the PV.

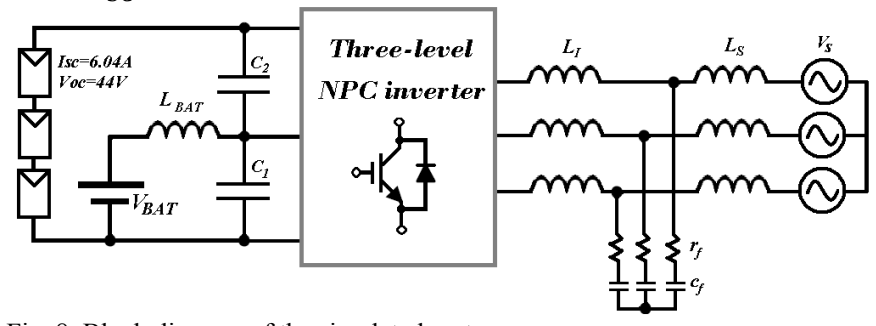

Fig. 8. Block diagram of the simulated system

In the simulation, it is assumed that $I_{S C}$ will change with different irradiances. With a solar irradiation of $1000 \mathrm{~W} / \mathrm{m}^{2}$, $I_{S C}$ is equal to $6.04 \mathrm{~A}$ and the open circuit voltage of the PV panels will be equal to $V_{o C}=44 \mathrm{~V}$. The main parameters of the simulated system are given in Table I.

Table I. Parameters of the simulated system

\begin{tabular}{|c|l|l|l|l|l|}
\hline$V_{B A T}$ & Vs (line) & $L_{B A T}$ & $\mathrm{C}_{1}, \mathrm{C}_{2}$ & \multicolumn{1}{|c|}{$L_{I}$} & \multicolumn{1}{c|}{$L_{S}$} \\
\hline $60 \mathrm{~V}$ & $50 \mathrm{~V}$ & $5 \mathrm{mH}$ & $1000 \mathrm{uF}$ & $500 \mathrm{uH}$ & $900 \mathrm{uH}$ \\
\hline$r_{f}$ & $C_{f}$ & $\mathrm{~K}_{\mathrm{p}}$ & $\mathrm{K}_{\mathrm{i}}$ & $\mathrm{G}_{1}$ & $\mathrm{G}_{2}$ \\
\hline $3 \Omega$ & $14 \mathrm{uF}$ & 2.9 & 1700 & 1 & 200 \\
\hline
\end{tabular}

As discussed in subsection III-B, $\mathrm{G}_{2}$ must be much more than $\mathrm{G}_{1}$ in order to achieve the MPPT condition and to have the flexibility to charge and discharge of the battery. Based on our experiments, any value more than 100 is suitable for this ratio. On the other hand, because the ratio of $G_{2} / G_{1}$ will only affect the short-vector selection, increasing this ratio will not affect other results. This value has been selected to be 200 to have good control on Vdc, as shown in Table I.

The role of $\mathrm{L}_{\mathrm{BAT}}$, is to smooth the battery current, especially in the transient condition. A wide range of values are acceptable for the inductor value, however, decreasing its value will increase the current overshoot of the battery. Also, its value is dependent of its adjacent capacitor value and its transient voltages. Due to the practical considerations (such as size and cost), the value of $\mathrm{L}_{\mathrm{BAT}}$ is preferred to be low and has been chosen to be $5 \mathrm{mH}$ based our simulation studies.

The values of $\mathrm{K}_{\mathrm{p}}$ and $\mathrm{K}_{\mathrm{i}}$ are selected by modelling the system in the dq-frame. The current control loop can be converted to a simple system after using the decoupling technique shown in Fig 7. The details of this method can be found in [22].

For theoretical purposes, two different scenarios have been simulated to investigate the effectiveness of the proposed topology and the control algorithm using a step change in the reference inputs under the following conditions.

1. The effect of a step change in the requested active and reactive power to be transferred to the grid when the solar irradiance is assumed to be constant.

2. The effect of a step change of the solar irradiation when the requested active and reactive power to be transmitted to the grid are assumed to be constant.

In a practical system, a slope controlled change in the reference input is usually used rather than a step change to reduce the risk of mathematical internal calculation errors when working with a limited precision microprocessor system and also to prevent the protection system activation. Furthermore in practical situations, the inputs of the systems normally do not change instantaneously as a step change, such as the sun irradiation.

With this practical application in mind, the proposed system is simulated using a slope controlled change in the requested active power to be transferred to the grid when the solar irradiance is assumed to be constant. To validate this, a laboratory test is carried out using the same scenario and the experimental results given in Section V can be compared with the results from the simulation.

\section{A. First Theoretical Scenario}

In the first scenario, it is assumed that the solar irradiation will produce $I_{S C}=5.61 \mathrm{~A}$ in the PV module according to (21). The MPPT control block, shown in Fig. 7, determines the requested $\mathrm{PV}$ module voltage, $V_{d c}^{*}$, which is $117.3 \mathrm{~V}$ to achieve the maximum power from the PV system that can generate $558 \mathrm{~W}$ of electrical power.

The requested active power to be transmitted to the grid is initially set at $662 \mathrm{~W}$ and is changed to $445 \mathrm{~W}$ at time $t=40$ $\mathrm{ms}$ and the reactive power changes from zero to $250 \mathrm{VAr}$ at time $t=100 \mathrm{~ms}$.

Fig. 9 shows the results of the first scenario simulation. Fig 9(a) and Fig 9(b) show that the proposed control system has 
correctly followed the requested active and reactive power and Fig. 9(c) shows that the PV voltage has been controlled accurately (to be $177.3 \mathrm{~V}$ ) to obtain the maximum power from the PV module. Fig. 9(d) shows that battery is discharging when the grid power is more than the PV power, and it is charging when the PV power is more than the grid power. Fig. 9(d) shows that before time $t=40 \mathrm{~ms}$, the battery discharges at $1.8 \mathrm{~A}$ since the power generated by the PV is insufficient. After time $t=40 \mathrm{~ms}$, the battery current is about $-1.8 \mathrm{~A}$, signifying that the battery is being charged from the extra power of the PV module. Fig. 9(e) shows the inverter AC side currents and Fig. 9(f) shows the grid side currents with a total harmonic distortion (THD) less than $1.29 \%$ due to the LCL filter. The simulation results in Fig. 9 show that the whole system produces a very good dynamic response.
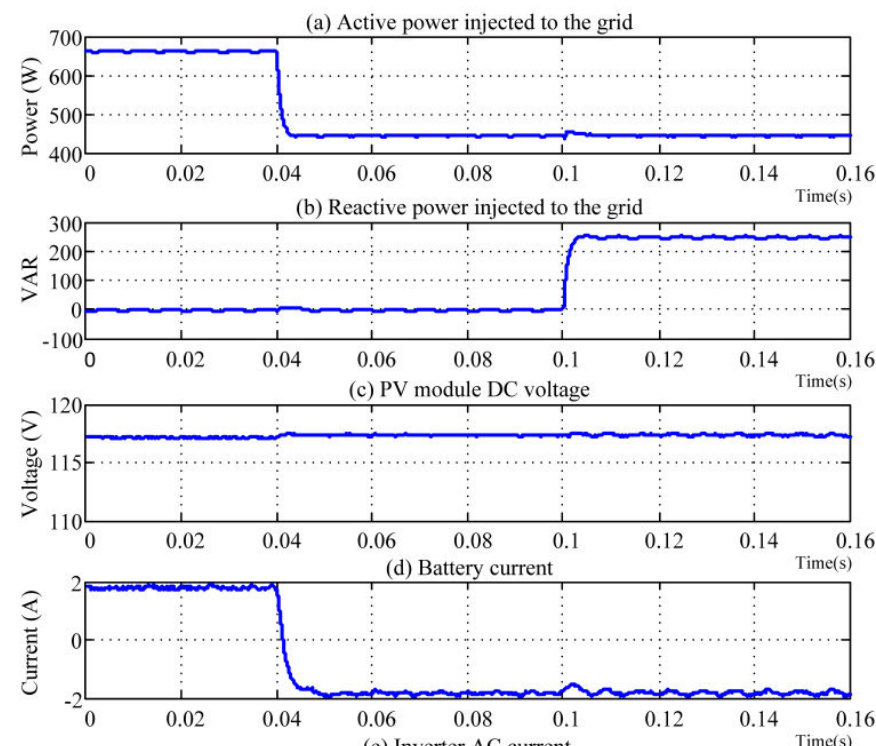
(e) Inverter AC current
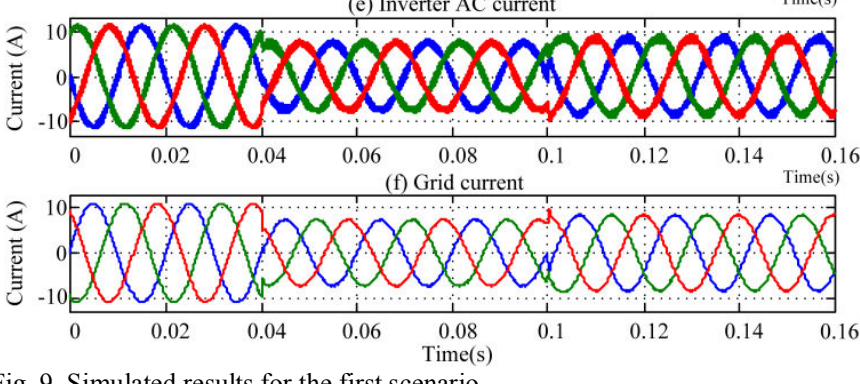

Fig. 9. Simulated results for the first scenario.

Fig. 10 shows the inverter waveforms for the same scenario. Fig. 10(a) shows the line-to-line voltage, $V_{a b}$ and Fig. 10(b) shows the phase to mid-point voltage of the inverter, $V_{a o}$. Figs $10(\mathrm{c})-10(\mathrm{e})$ show $V_{a o}, V_{o n}$ and $V_{a n}$ after mathematical filtering to determine the average value of the PWM waveforms.

\section{B. Second Theoretical Scenario}

In the second scenario, it is assumed that the solar irradiation will change such that the PV module will produce $I_{S C}=4.8 \mathrm{~A}, 4 \mathrm{~A}$ and $5.61 \mathrm{~A}$. The MPPT control block determines that $V_{d c}^{*}$ needs to be $115.6 \mathrm{~V}, 114.1 \mathrm{~V}$ and $117.3 \mathrm{~V}$ to achieve the maximum power from the PV units which can generate $485 \mathrm{~W}, 404 \mathrm{~W}$ and $558 \mathrm{~W}$ respectively.

The requested active power to be transmitted to the grid is set at a constant $480 \mathrm{~W}$ and the reactive power is set to zero during the simulation time.
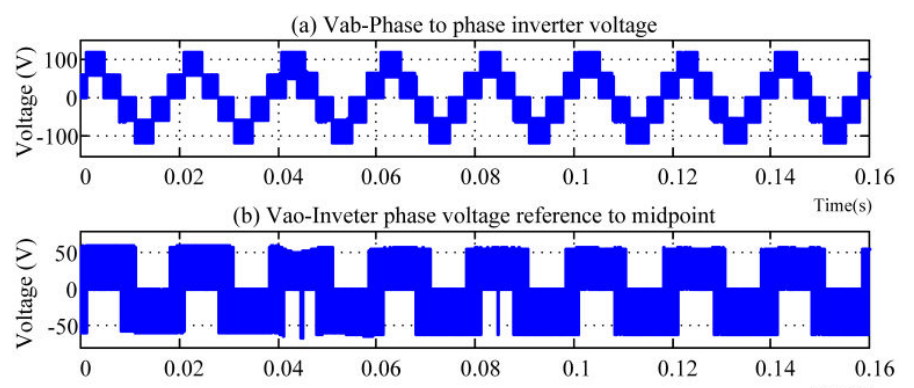
(c) Filtered Vao-Filtered inverter phase voltage reference to midpoint Time(s)
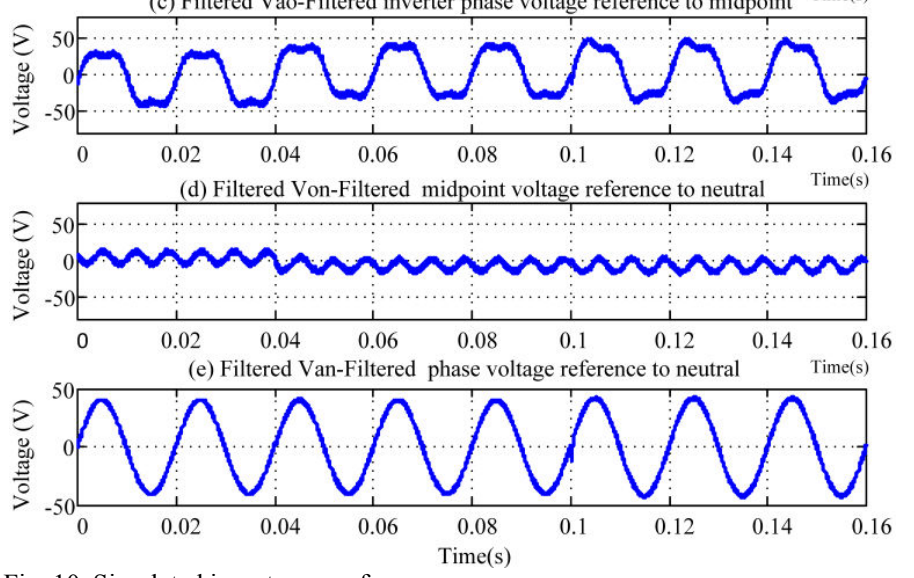

Fig. 10. Simulated inverter waveforms

Fig. 11 shows the results of the second scenario simulation. Fig. 11(a) shows that the inverter is able to generate the requested active power. Fig. 11(b) shows that the PV voltage was controlled accurately for different solar irradiation values to obtain the relevant maximum power from the PV modules.

Fig. 11(c) shows that the charging and discharging of the battery are correctly performed. The battery has supplemented the PV power generation to meet the requested demand by the grid. Fig. 11(d) illustrates that the quality of the waveforms of the grid side currents are acceptable, which signifies that the correct PWM vectors are generated by the proposed control strategy. By using the proposed strategy, the inverter is able to provide a fast transient response. Fig. 11(e) shows the a-phase voltage and current of the grid, which are always in-phase signifying that the reactive power is zero at all times.

\section{Practically oriented simulation}

In the third simulation, the requested active power to be transmitted to the grid is initially set at $295 \mathrm{~W}$ and, at time $t=$ $40 \mathrm{~ms}$, the requested active power starts to reduce as a slope controlled change and is finally stays constant at $165 \mathrm{~W}$ at $\mathrm{t}=$ $90 \mathrm{~ms}$. It is assumed that the solar irradiation will produce $I_{S C}=2.89 \mathrm{~A}$ in the PV module according to (21). The requested PV module voltage $V_{d c}^{*}$, to achieve MPPT condition will be $112.8 \mathrm{~V}$ to generate $305 \mathrm{~W}$ of electrical power.

Figure 12(a) shows that the active power transmitted to the grid reduces and follows the requested active power. Fig 
12(b) shows the battery current which is about $0.1 \mathrm{~A}$ before $t=$ $40 \mathrm{~ms}$ and then because of the reduced power transmission to the grid with a constant PV output, the battery charging current is increased and finally fixed at about 2.2A. Fig 12(c) shows the AC inverter currents slowly decreasing starting from $3.4 \mathrm{~A}_{\mathrm{rms}}$ at $\mathrm{t}=40 \mathrm{~ms}$ and finally stays constant at $1.9 \mathrm{~A}_{\mathrm{rms}}$ at $\mathrm{t}=90 \mathrm{~ms}$.
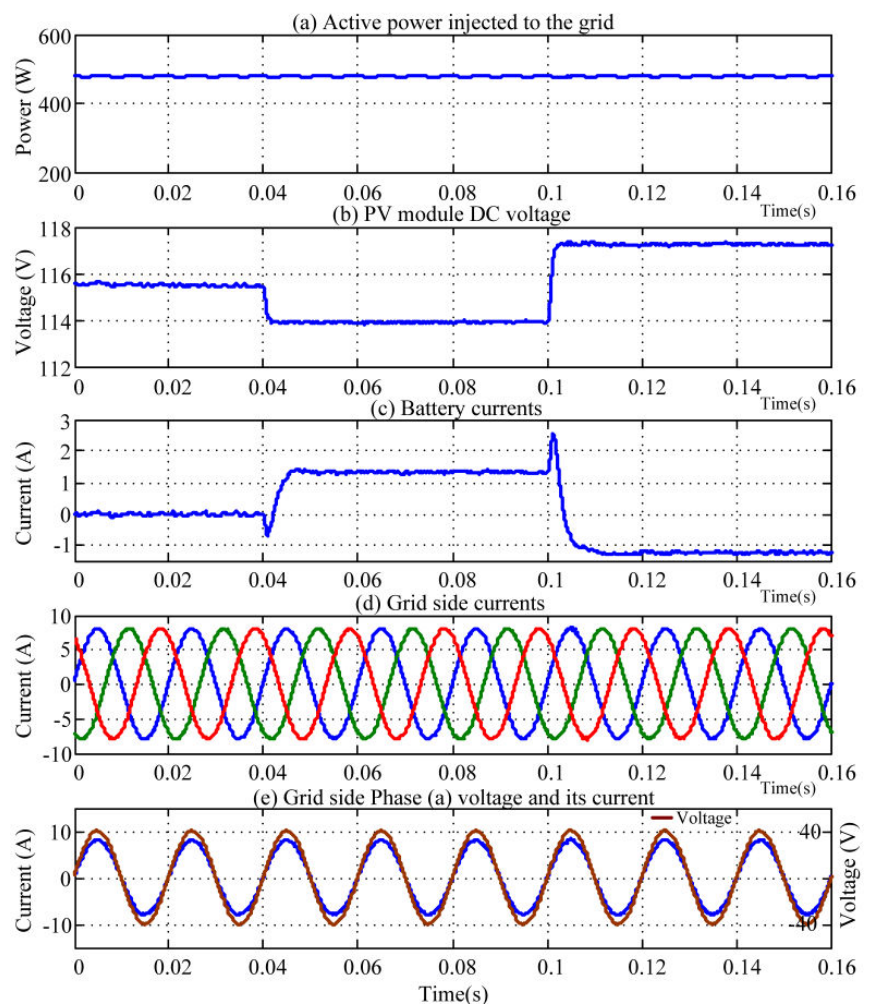

Fig. 11. Simulated results for the second scenario

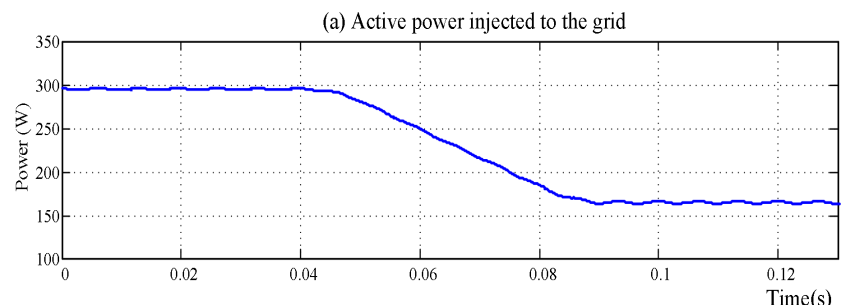

(b) Battery current
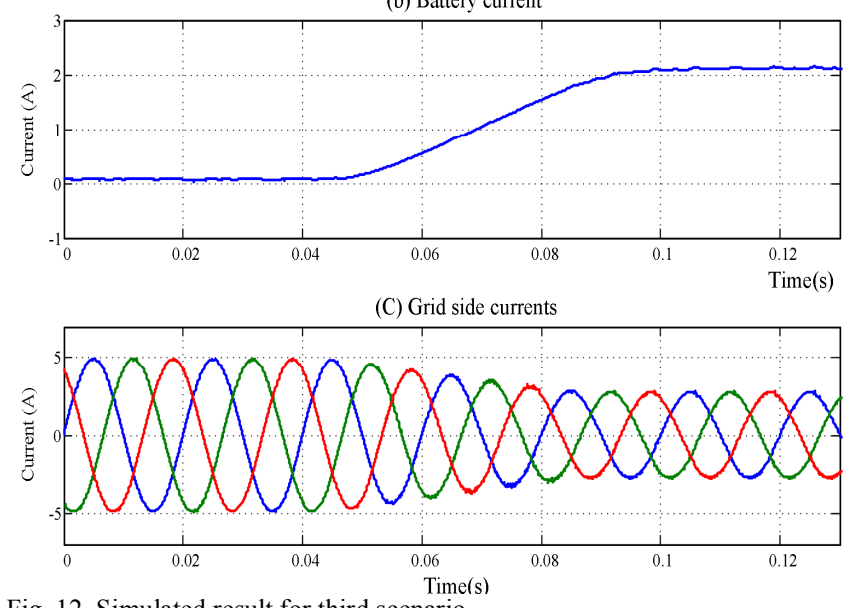

During this simulation the DC voltage is held at $112.8 \mathrm{~V}$ to fulfill the MPPT requirement. It is important to note that during the simulations, the DC bus is working under unbalanced condition because the battery voltage during the simulation is equal to $60 \mathrm{~V}$ and therefore this particular scenario will not allow equal capacitor voltages.

\section{EXPERIMENTAL RESULT}

A prototype system, as shown in Fig. 13, is built in the lab to validate the operation and the effectiveness of the proposed system. The inverter and the control part of the prototype system is configurable to be used as a three-phase five-level floating capacitor based active neutral point clamp (5LANPC) inverter, a three-phase three-level ANPC inverter and a three-phase three-level NPC inverter applications. For the purpose of this paper, the prototype system is configured as a three-phase three-level NPC inverter. In this case, some of the switches will be continually set to OFF or ON.

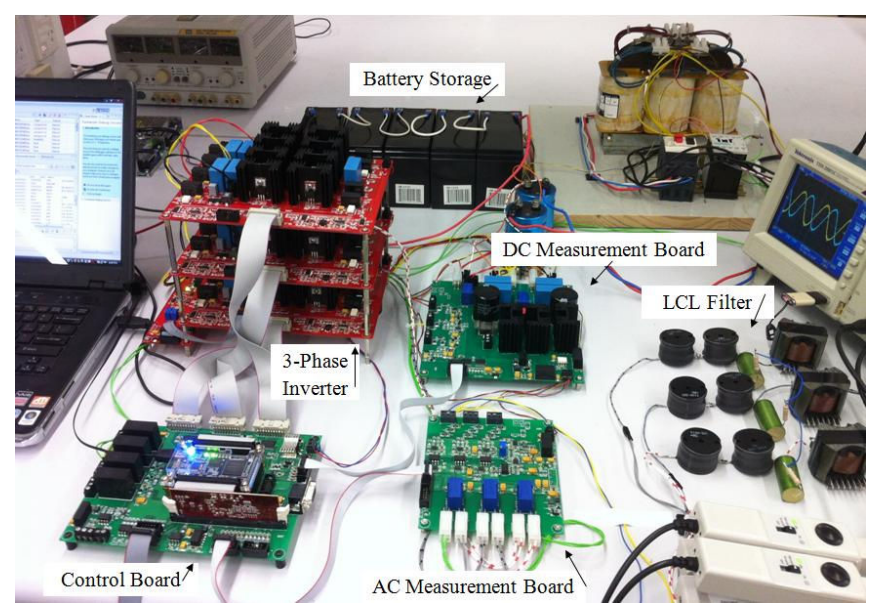

Fig. 13. Experimental setup

The output from the California Instruments programmable arbitrary waveform generator is used to emulate the grid and the output from a programmable solar array simulator (Elgar TerraSAS) from AMETEK is used to emulate the PV arrays. The Texas instrument TMS320F28335 control card and the Altera Cyclone ${ }^{\circledR} I V$ EP4CE22F17C6N FPGA card are used in the control board to provide the necessary control implementation ability

.The implemented system specification is approximately similar to the same system configuration and values presented in the simulation section with the parameters given in Table I. The experimental parameters are given in Table II.

Table II. Parameters of the experimental setup

\begin{tabular}{|c|c|c|c|c|}
\hline$V_{B A T}$ & $V_{s}($ line $)$ & $L_{B A T}$ & $r_{L_{B A T}}$ & $C_{1}, C_{2}$ \\
\hline $63.2 \mathrm{~V}$ & $49.9 \mathrm{~V}$ & $5.2 \mathrm{mH}$ & $0.32 \Omega$ & $1020 \mathrm{uF}$ \\
\hline \hline$r_{f}$ & $C_{f}$ & $L_{i}$ & $L_{S}$ & $r_{L_{S}}$ \\
\hline $3.3 \Omega$ & $15 \mathrm{uF}$ & $540 \mathrm{uH}$ & $910 \mathrm{uH}$ & $0.1 \Omega$ \\
\hline
\end{tabular}




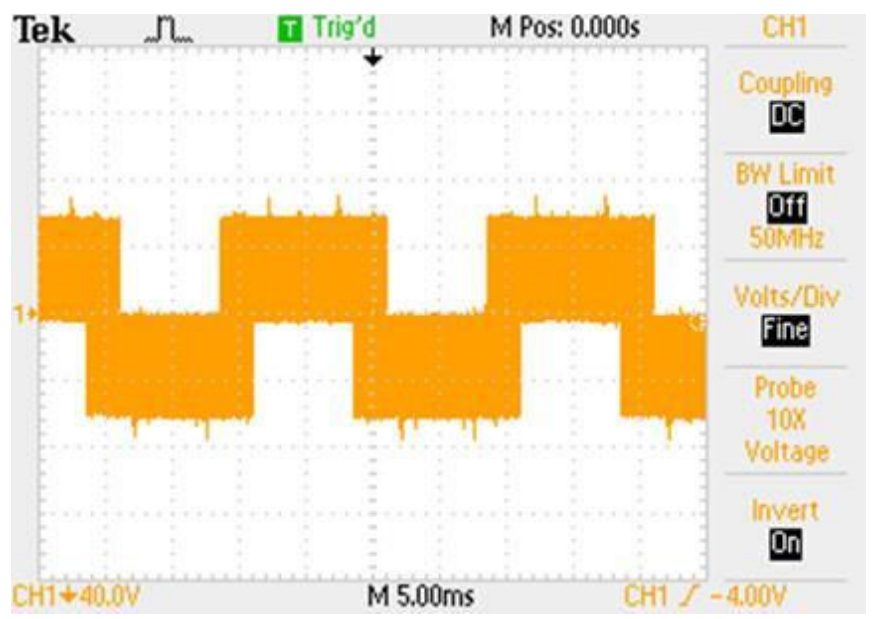

Fig. 14. Inverter phase 'a' voltage reference to the inverter middle point, Vao.

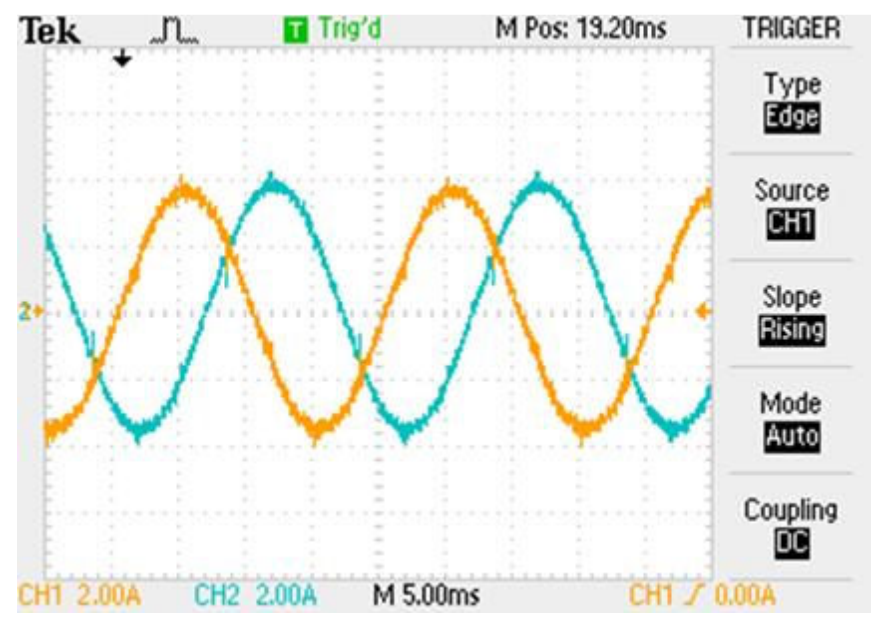

Fig. 15. Phase 'a' and phase ' $b$ ' gird side current

The experimental results are shown in Fig. 14 to Fig. 19. Figs. 15 - 16 show the steady state results when $220 \mathrm{~W}$ active power is transferred to the grid from PV and about $75 \mathrm{~W}$ is being absorbed by the battery.

Fig. 14 shows the PWM output voltage of phase ' $a$ ' of the inverter with reference to the midpoint of the inverter where $T_{s}$ is set to be $100 \mu$ s which agrees with our simulation.

Fig. 15 shows phase 'a' and 'b' steady state grid side currents showing proper switching performance of the inverter. Fig. 16 shows the inverter and grid phase 'a' currents to show the effectiveness of the designed LCL filter.

Figure 17 shows the battery and phase 'a' grid current when PV output is reducing. Initially the battery current is positive suggesting that the battery is absorbing power (around $75 \mathrm{~W}$ ) and then as the PV output is reducing, the battery slowly reduces its absorbing power and then starts to discharge power to supplement the PV output, to maintain constant power to the grid as shown in the phase ' $a$ ' grid current, which remains constant as the battery current is changing.

To validate the simulation results from Section IV-C, a new test was carried out with a similar condition as described in Section IV-C. The results are shown in Fig. 18. In the test, the PV simulator generates about $300 \mathrm{~W}$ power. In this condition

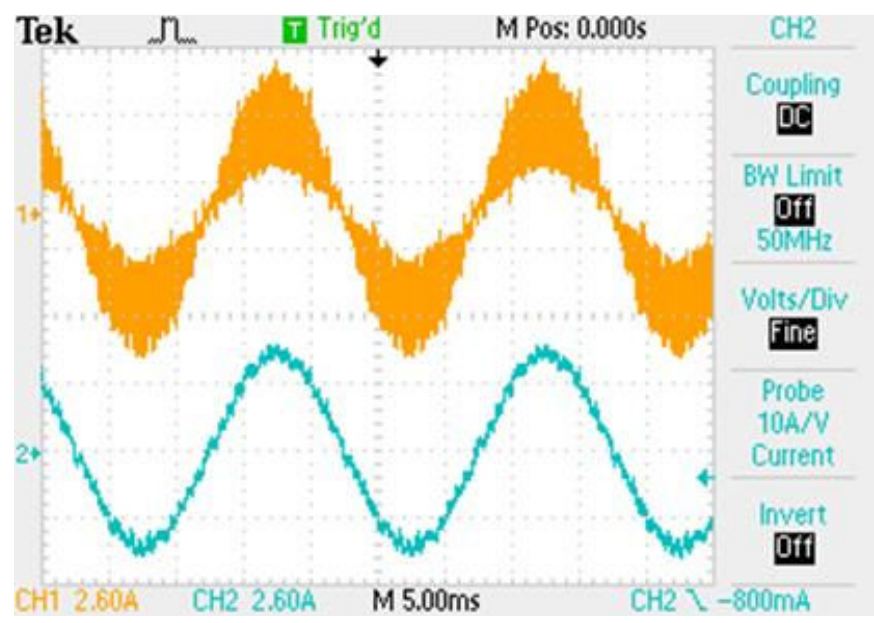

Fig. 16. Inverter phase 'a' current, $\mathrm{CH} 1$; Grid side phase 'a' current, $\mathrm{CH} 2$

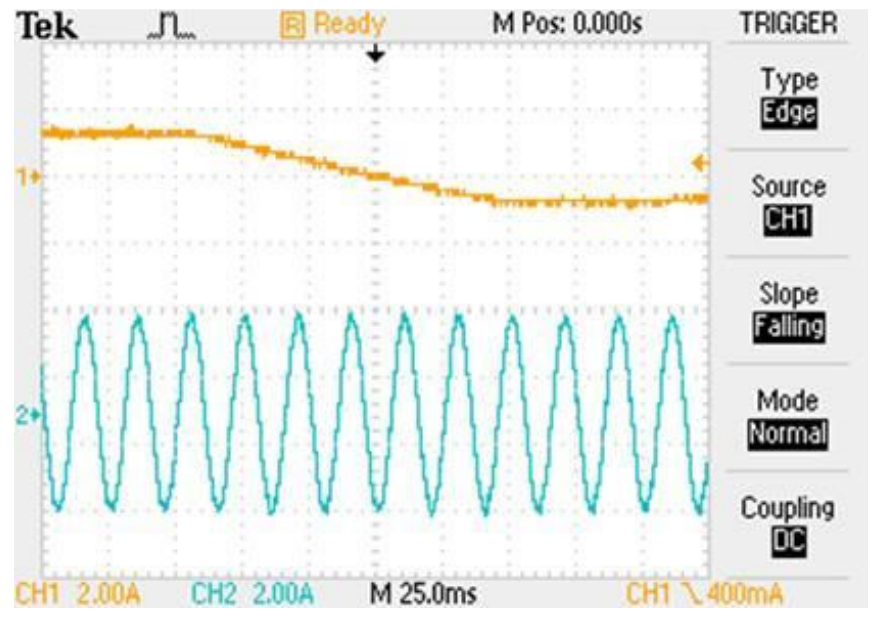

Fig. 17. Battery current, $\mathrm{CH} 1$ and phase 'a' grid current, $\mathrm{CH} 2$.

the DC side voltage of the inverter is about $112.3 \mathrm{~V}$ to meet the MPPT condition.

The battery voltage is about $63.6 \mathrm{~V}$ during the charging time and the voltage of the lower capacitor, $\mathrm{V}_{\mathrm{C} 1}$, is about $64.2 \mathrm{~V}$ which shows that the inverter is working under unbalanced DC voltage condition to fulfil the power transmission requirements.

Figure 18 shows the situation when initially the battery current is around zero and the grid power is only supplied by PV power. Then by reducing the requested power from the grid, the extra power from the PV is transferred to the battery causing the battery current goes positive which means that the battery is absorbing power. The reduction of transferred power to the grid is shown in the phase 'a' grid current.

Fig. 19 shows the steady state phase ' $a$ ' grid voltage and current waveforms showing that they are in phase and hence power factor can be controlled to be unity.

\section{CONCLUSION}

A novel topology for a three-level neutral point clamped voltage source inverter that can integrate both renewable energy and battery storage on the DC side of the inverter has been presented. A theoretical framework of a novel extended 


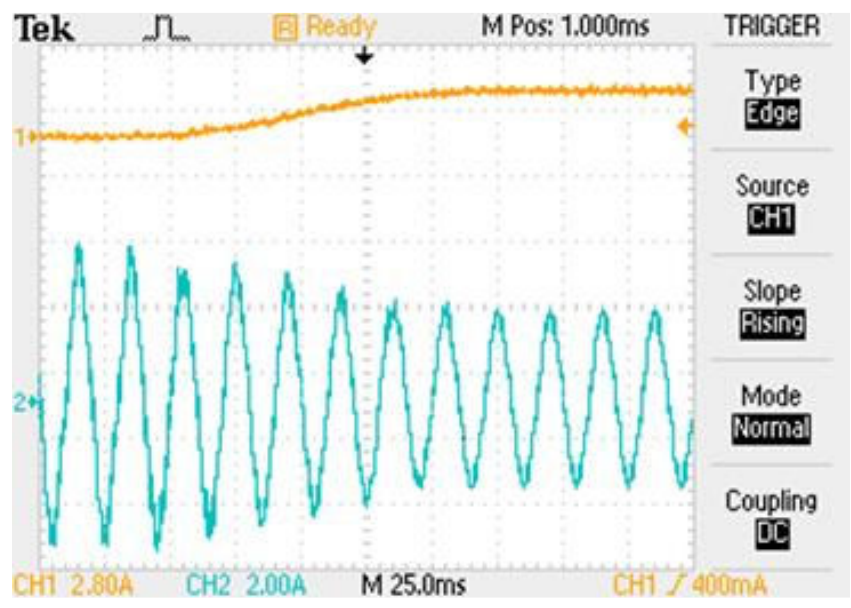

Fig. 18. Battery current, $\mathrm{CH} 1$ and phase 'a' grid current, $\mathrm{CH} 2$.

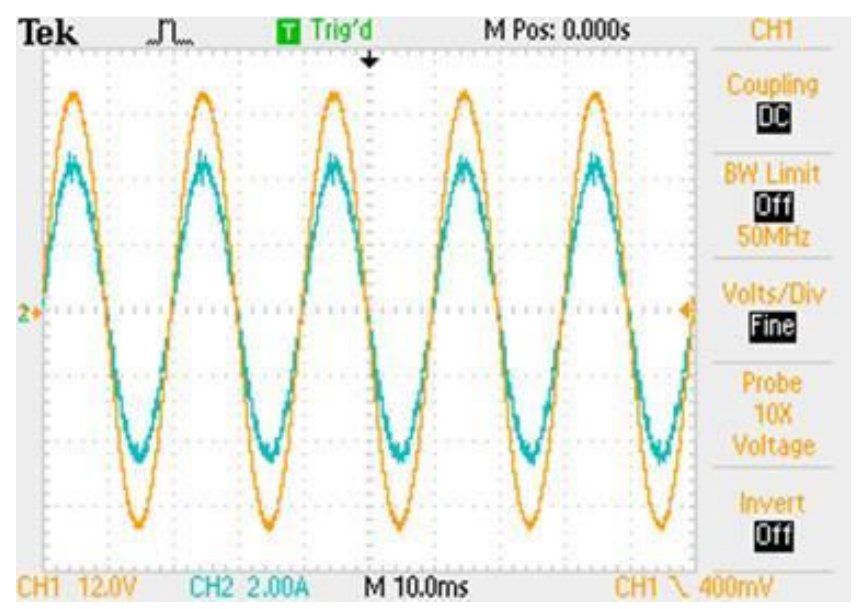

Fig. 19. Phase 'a' grid voltage and current waveforms

unbalance three-level vector modulation technique that can generate the correct AC voltage under unbalanced DC voltage conditions has been proposed. A new control algorithm for the proposed system has also been presented in order to control power flow between solar PV, battery, and grid system while MPPT operation for the solar PV is achieved simultaneously. The effectiveness of the proposed topology and control algorithm was tested using simulations and results are presented. The results demonstrate that the proposed system is able to control AC side current, and battery charging and discharging currents at different levels of solar irradiation. The results from experiments using a prototype built in the lab have validated the proposed topology to control both PV and battery storage in supplying power to the AC grid.

\section{REFERENCES}

[1] O. M. Toledo, D. Oliveira Filho, and A. S. A. C. Diniz, "Distributed photovoltaic generation and energy storage systems: A review," Renewable and Sustainable Energy Reviews, vol. 14, pp. 506-511, 2010.

[2] M. Bragard, N. Soltau, S. Thomas, et al., "The Balance of Renewable Sources and User Demands in Grids: Power Electronics for Modular Battery Energy Storage Systems," IEEE Transactions on Power Electronics, vol. 25, pp. 3049-3056, 2010.

[3] A. Yazdani and P. P. Dash, "A Control Methodology and Characterization of Dynamics for a Photovoltaic (PV) System Interfaced With a Distribution Network," IEEE Transactions on Power Delivery, vol. 24, pp. 1538-1551, 2009.

[4] A. Yazdani, A. R. Di Fazio, H. Ghoddami, et al., "Modeling Guidelines and a Benchmark for Power System Simulation Studies of Three-Phase Single-Stage Photovoltaic Systems," IEEE Transactions on Power Delivery, vol. 26, pp. 1247-1264, 2011.

[5] M. A. Abdullah, A. H. M. Yatim, C. W. Tan, et al., "A review of maximum power point tracking algorithms for wind energy systems," Renewable and Sustainable Energy Reviews, vol. 16, pp. 3220-3227, 2012.

[6] S. Burusteta, J. Pou, S. Ceballos, et al., "Capacitor voltage balance limits in a multilevel-converter-based energy storage system," in Proceedings of the 2011-14th European Conference on Power Electronics and Applications (EPE 2011), 2011, pp. 1-9.

[7] L. Xinchun, G. Shan, J. Li, et al., "A new control strategy to balance neutral-point voltage in three-level NPC inverter," in IEEE 8th International Conference on Power Electronics and ECCE Asia (ICPE \& ECCE), 2011, pp. 2593-2597.

[8] J. Rodriguez, S. Bernet, P. K. Steimer, et al., "A Survey on NeutralPoint-Clamped Inverters," IEEE Transactions on Industrial Electronics, vol. 57, pp. 2219-2230, 2010.

[9] A. Lewicki, Z. Krzeminski, and H. Abu-Rub, "Space-Vector Pulsewidth Modulation for Three-Level NPC Converter With the Neutral Point Voltage Control," IEEE Transactions on Industrial Electronics, vol. 58, pp. 5076-5086, 2011.

[10] J. Pou, D. Boroyevich, and R. Pindado, "Effects of imbalances and nonlinear loads on the voltage balance of a neutral-point-clamped inverter," IEEE Transactions on Power Electronics, vol. 20, pp. 123-131, 2005.

[11] Z. Huibin, S. Jon Finney, A. Massoud, et al., "An SVM Algorithm to Balance the Capacitor Voltages of the Three-Level NPC Active Power Filter," IEEE Transactions on Power Electronics, vol. 23, pp. 2694-2702, 2008.

[12] J. Zaragoza, J. Pou, S. Ceballos, et al., "Voltage-Balance Compensator for a Carrier-Based Modulation in the Neutral-Point-Clamped Converter," IEEE Transactions on Industrial Electronics, vol. 56, pp. 305-314, 2009.

[13] W. Chenchen and L. Yongdong, "Analysis and Calculation of ZeroSequence Voltage Considering Neutral-Point Potential Balancing in Three-Level NPC Converters," IEEE Transactions on Industrial Electronics, vol. 57, pp. 2262-2271, 2010.

[14] S. Busquets-Monge, S. Somavilla, J. Bordonau, et al., "Capacitor Voltage Balance for the Neutral-Point- Clamped Converter using the Virtual Space Vector Concept With Optimized Spectral Performance," IEEE Transactions on Power Electronics, vol. 22, pp. 1128-1135, 2007.

[15] S. Busquets-Monge, J. Bordonau, D. Boroyevich, et al., "The nearest three virtual space vector PWM - a modulation for the comprehensive neutral-point balancing in the three-level NPC inverter," IEEE Power Electronics Letters, vol. 2, pp. 11-15, 2004.

[16] J. Pou, J. Zaragoza, S. Ceballos, et al., "A Carrier-Based PWM Strategy With Zero-Sequence Voltage Injection for a Three-Level Neutral-PointClamped Converter," IEEE Transactions on Power Electronics, vol. 27, pp. 642-651, 2012.

[17] J. Wei-dong, D. Shao-wu, C. Liu-chen, et al., "Hybrid PWM Strategy of SVPWM and VSVPWM for NPC Three-Level Voltage-Source Inverter," IEEE Transactions on Power Electronics, vol. 25, pp. 26072619, 2010.

[18] J. Zaragoza, J. Pou, S. Ceballos, et al., "A Comprehensive Study of a Hybrid Modulation Technique for the Neutral-Point-Clamped Converter," IEEE Transactions on Industrial Electronics, vol. 56, pp. 294-304, 2009

[19] Z. Jian-Yong, S. Zhang-Liang, M. Jun, et al., "An Improved NeutralPoint Voltage Balancing Algorithm for the NPC Three-Level Inverter Based on Virtual Space Vector PWM," in International Conference on Electrical and Control Engineering (ICECE), 2010, pp. 3283-3287.

[20] J. Pou, D. Boroyevich, and R. Pindado, "New feedforward space-vector PWM method to obtain balanced AC output voltages in a three-level neutral-point-clamped converter," IEEE Transactions on Industrial Electronics, vol. 49, pp. 1026-1034, 2002.

[21] M. G. Villalva, J. R. Gazoli, and E. R. Filho, "Comprehensive Approach to Modeling and Simulation of Photovoltaic Arrays," IEEE Transactions on Power Electronics, vol. 24, pp. 1198-1208, 2009.

[22] A. Yazdani and R. Iravani, Voltage-Sourced Converters in Power Systems: Wiley, 2010. 